\section{Ultrasound-guided ethanol ablation for cystic thyroid nodules: effectiveness of small amounts of ethanol in a single session}

\author{
Woojin Cho ${ }^{1}$, Jung Suk $\mathrm{Sim}^{2}$, So Lyung Jung ${ }^{3}$ \\ Departments of ${ }^{1}$ Otolaryngology-Head and Neck Surgery and ${ }^{2}$ Radiology, Withsim Clinic, \\ Seongnam; ${ }^{3}$ Department of Radiology, Yeouido St. Mary's Hospital, College of Medicine, The \\ Catholic University of Korea, Seoul, Korea
}

Purpose: The aim of this study was to evaluate the efficacy of ethanol ablation (EA) in the treatment of cystic thyroid nodules using low-dose ethanol regardless of the initial volume of the nodule or properties of the aspirate.

Methods: Sixty-one nodules in 60 patients were treated with EA from October 2013 to January 2020. In each patient, EA was performed only once, using less than $5 \mathrm{~mL}$ of ethanol (99.5\%) instilled and removed completely after a few minutes of retention. Nodule volume, the symptom score, the cosmetic score, and complications were evaluated before and after treatment. The therapeutic success rate (TSR) and volume reduction rate (VRR) according to nodule volume and properties of the aspirate were evaluated. Therapeutic success was defined as the absence of any residual fluid or sufficient volume reduction $(\geq 50 \%)$ with improvement of nodule-related symptoms. Results: The 61 nodules comprised 38 pure cysts and 23 predominantly cystic nodules. The initial nodule volume was $21.9 \pm 15.2 \mathrm{~mL}$ (range, 4.4 to $77.2 \mathrm{~mL}$ ). The TSR was $88.5 \%(100 \%$ in pure cysts and $69.6 \%$ in predominantly cystic nodules, $P<0.001$ ). The TSR of pure cysts was $100 \%$ regardless of nodule volume and properties of the aspirate. In predominantly cystic nodules, the TSR and VRR gradually decreased as volume increased. One patient experienced arrhythmia during the procedure, but completely recovered without sequelae.

Conclusion: Single-session EA using low-dose ethanol might be effective for the treatment of symptomatic cystic thyroid nodules regardless of the initial cyst volume and properties of the aspirate, especially in pure cysts.

Keywords: Thyroid; Thyroid nodule; Thyroid cyst; Ethanol; Sclerotherapy; Ablation

\section{Introduction}

Most thyroid cystic nodules are benign and asymptomatic; however, some cystic nodules grow over time and may induce symptoms or cosmetic problems [1]. In these cases, simple aspiration can be considered as a first-line option for symptom control. However, the recurrence rate after
ULTRA

SONO

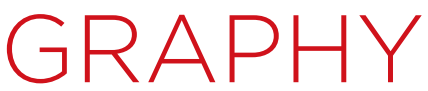

ORIGINAL ARTICLE

https://doi.org/10.14366/usg.20170 pISSN: 2288-5919 • elSSN: 2288-5943

Ultrasonography 2021;40:417-427

Received: October 29, 2020

Revised: December 21, 2020

Accepted: December 22, 2020

Correspondence to:

So Lyung Jung, MD, PhD, Department of Radiology, Yeouido St. Mary's Hospital, College of Medicine, The Catholic University of Korea, 10, 63ro, Yeongdeungpo-gu, Seoul 07345, Korea

Tel. $+82-2-3779-1019$

Fax. $+82-2-783-5288$

E-mail: sljung1@catholic.ac.kr

This is an Open Access article distributed under the terms of the Creative Commons Attribution NonCommercial License (http://creativecommons.org/ licenses/by-nc/4.0/) which permits unrestricted noncommercial use, distribution, and reproduction in any medium, provided the original work is properly cited.

Copyright (C) 2021 Korean Society of Ultrasound in Medicine (KSUM)

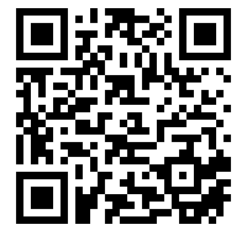

How to cite this article:

Cho W, Sim JS, Jung SL. Ultrasound-guided ethanol ablation for cystic thyroid nodules: effectiveness of small amounts of ethanol in a single sessio. Ultrasonography. 2021 Jul;40(3):417-427. 
simple aspiration is as high as $50 \%-80 \%$ [2]. If the symptoms are refractory to repetitive aspirations, ultrasound-guided ethanol ablation (EA) can be an alternative to surgery. EA has been widely used since Rozman et al. applied it for the first time to cystic thyroid nodules in 1989 [3].

In general, two sclerotic procedures have been described in previous studies: (1) using simple ethanol injection after aspiration of the internal cystic contents of thyroid nodules; (2) evacuating ethanol completely from a cystic nodule after few minutes of retention following the former method. No difference has been found between these two methods in the complication and success rates [4]. Therefore, the choice of whether to perform ethanol injection with aspiration or retention may depend on the operator's preference. The reported independent predictors of EA include initial volume and vascularity in predominantly cystic nodules, but no factor is known to be independently related to efficacy in pure cysts [5]. In et al. [6] reported that complete aspiration of cystic components was associated with the efficacy of EA in benign thyroid cystic nodules.

However, a sufficient consensus has not yet been established regarding the number of sessions and the total amount of ethanol to use for instillation [7]. Most studies reported success rates without clearly distinguishing between single- and multiple-session therapy, but single-session therapy seemed to work well enough (success rates of $64 \%-100 \%$ ) according to some studies $[3,4,8-$ 10]. Moreover, the amount of ethanol injected was decided mostly by certain empirical proportions $(10 \%-150 \%)$ relative to the volume of nodule or the aspirate, and these proportions have varied across studies $[5,11-14]$. The possibility of using low-dose ethanol in EA was presented by Zingrillo et al. $[15,16]$, who achieved high efficacy by injecting 2-4 $\mathrm{mL}$ of ethanol depending on the nodule volume without removal [8]. In their studies, additional multiple EA sessions were performed with ethanol injections that increased to up to $10 \mathrm{~mL}$ per session if the volume reduction was less than $50 \%$ of the initial nodule volume. To the best of our knowledge, studies focusing on minimal usage of ethanol (low-dose and single-session) in EA have not been published. We aimed to evaluate the efficacy of single-session EA using low-dose ( $\leq 5 \mathrm{~mL}$ ) ethanol regardless of the initial volume of the nodule or properties of the aspirate.

\section{Materials and Methods}

The national public Institutional Review Board approved this retrospective study (P01-202005-21-001) with a waiver for consent forms. However, all patients provided written informed consent prior to fine-needle aspiration cytology (FNAC) and EA.

\section{Patient Selection}

From October 2013 to January 2020, a total 83 pure cysts or predominantly cystic thyroid nodules in 75 patients (54 women and 21 men; mean age, 44.2 years; range, 24 to 76 years) were treated with EA at Withsim Clinic. Most nodules were confirmed as benign by ultrasound-guided FNAC. In a few cases of pure cysts, the cytologic results were nondiagnostic or unsatisfactory, even with repeated fine-needle aspiration. EA was performed to treat recurrent pure cysts, regardless of nondiagnostic results [7]. All patients treated with EA had nodule-related pressure symptoms or cosmetic problems. The exclusion criteria were as follows: (1) patients who had undergone any previous chemical or thermal ablative procedures for the target lesion; (2) patients who did not receive any follow-up after treatment.

Fig. 1 shows the process of study selection. Among the 83 nodules, 13 were excluded because of missing follow-up data after EA. Another nine nodules treated with other ablative procedures before EA were excluded from the study. Among those nine nodules, three nodules had been treated with radiofrequency ablation (RFA) and six nodules had previously received EA. Finally, 61 nodules in 60 patients (42 women and 18 men; mean age, 43.1 years; range, 24 to 76 years) were included in the current study.

\section{Pre-procedure Evaluation}

All patients underwent ultrasonography and ultrasound-guided FNAC using an 8 to $17 \mathrm{MHz}$ linear probe (E-CUBE 15 EX, Alpinion Medical Systems Co., Ltd., Anyang, Korea), performed by one of two physicians (Cho W and Sim JS) with more than 10 years of experience. Nodule size, proportion of the cystic component, vascularity, and properties of the internal fluid content were assessed on the ultrasound examination and during FNAC. The volume $(V)$ of each nodule was calculated as: $V=\pi \times w \times d \times / / 6$, where $w$ is the width, $d$ is the depth, and $/$ is the length. Vascularity was graded into four categories ( 0 , no intranodular vascularity;

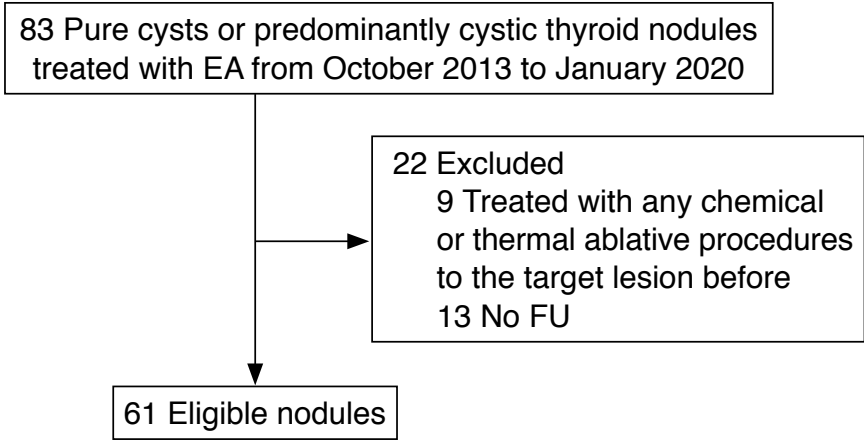

Fig. 1. Flowchart of the patient selection process. EA, ethanol ablation; FU, follow-up. 
1 , perinodular vascularity only; 2 , intranodular vascularity $<50 \%$; and 3 , intranodular vascularity $>50 \%)[5,17]$. The viscosity of the internal fluid content was classified as watery, mucoserous, or sticky (colloid). The color of the aspirate was also classified as pale yellowish, brownish, dark bloody, and red bloody [6]. The laboratory tests usually included a thyroid function test (measurements of thyrotropin, triiodothyronine, and free thyroxine), while a blood coagulation battery (bleeding time, prothrombin time, and activated partial thromboplastin time) was considered based on the patient's medical history or risk for hemorrhage. A symptom score was estimated using a $10-\mathrm{cm}$ visual analogue scale (graded from 0 to 10) by patients. The cosmetic score was measured by a physician (1, no palpable mass; 2 , no cosmetic problem but a palpable mass; 3 , a cosmetic problem on swallowing only; and 4 , a readily detected cosmetic problem) [7].

\section{EA Procedure}

All EA procedures were performed with ultrasound guidance by one head and neck surgeon (Cho W) having more than 10 years of experience in ultrasound-related practice, including ultrasound, FNAC, and chemical and thermal ablation for thyroid nodules. Cho W has been qualified for thyroid, head, and neck ultrasound examinations by the Korean Society of Ultrasound in Medicine since 2012.

EA was performed in an outpatient clinic. Patients were placed in a supine position with mild neck extension. In a sterile field, $2 \%$ lidocaine was injected at the skin puncture site and thyroid pericapsular space for pain control. A 17-gauge disposable needle

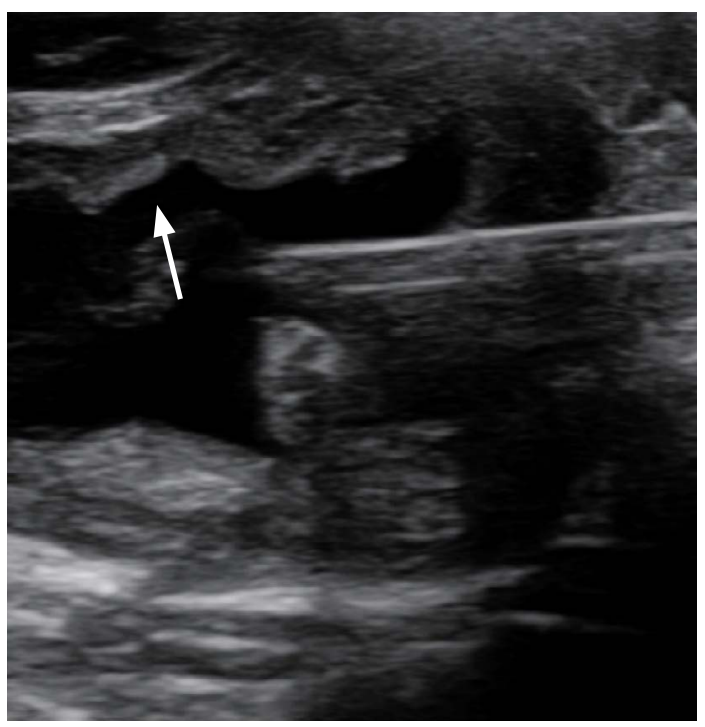

A (coaxial introducer needle, PT17094, M.D.L., Delebio, Sondrio, Italy) was inserted into the nodule under ultrasound guidance via the isthmic or para-isthmic area to prevent a change of needle position and ethanol leakage while swallowing during the procedure. To avoid injury of the vessels along the needle tract, color Doppler was applied before needle insertion. All procedures were done with a single puncture using a three-way connector. The internal contents were removed with the utmost care to prevent ex-vacuum hemorrhage [18]. Residual debris or colloids were removed as much as possible. For cases with high-viscosity colloid contents, repetitive room-temperature saline irrigation was used for dilution. At the end of the extraction procedure, a small amount of saline was injected and maintained for few seconds to verify the absence of leakage before ethanol instillation. If no leakage was observed, $99.5 \%$ sterile ethanol (Daihan Dehydrated Alcohol Inj., Dai Han Pharm. Co., Ltd., Seoul, Korea) was slowly instilled after total removal of the mixed saline. When the ethanol was instilled, the inner surface of the cyst changed to a hyperechoic line on ultrasonography (Fig. 2). Regardless of the volume of cystic nodule or aspirate, less than $5 \mathrm{~mL}$ of ethanol was injected, and the pattern of distribution was monitored until the entire inner surface showed echogenic change. After a few minutes, all the instilled ethanol was re-aspirated completely. At any point, if the patient complained of any atypical symptoms, such acute severe cervical pain or altered vital signs, which could be a sign of ethanol leakage, the ethanol was removed right away and the procedure was stopped. After removing the ethanol completely, the needle was withdrawn slowly from the neck with minimal negative pressure of the syringe to prevent leakage

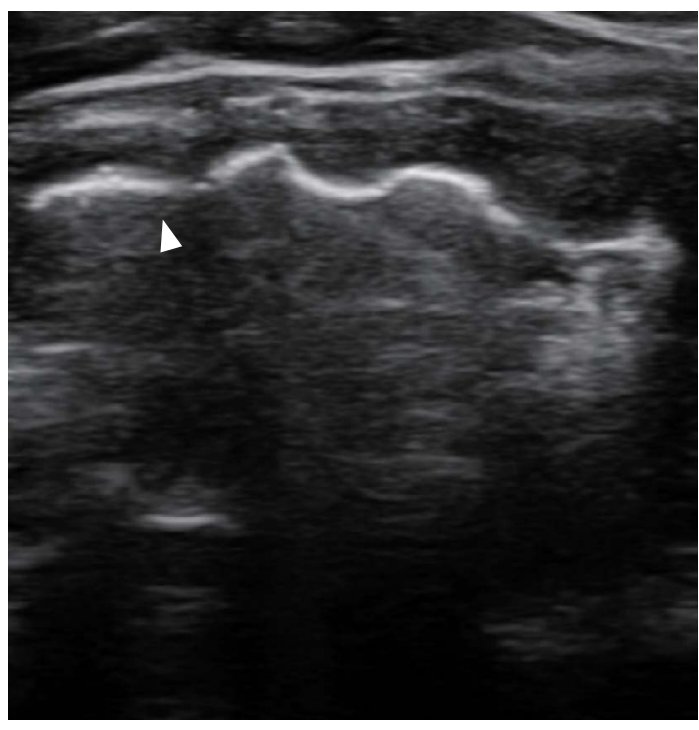

B

Fig. 2. Ultrasonography during ethanol ablation.

When ethanol is instilled, the inner surface of the cyst (arrow) (A) is changed to a hyperechoic line (arrowhead) (B). 
of the ethanol remaining inside the needle [5]. Gentle pressure was applied to the puncture site with sterile gauze, and the patient then remained under observation for an additional 30 minutes. During and after the procedure, any discomfort or complications were documented.

\section{Posttreatment Assessment}

The patients were followed up at 1, 3, 6, and 12 months after treatment. After 1 year, ultrasonography examinations were performed annually. Follow-up evaluations were conducted in the same manner as the preprocedural assessment using ultrasonography and a physical examination. The success of treatment was defined as the absence of any residual fluid or a sufficient volume reduction rate (VRR) $(\geq 50 \%)$ at the last follow-up with regression of nodule-related symptoms $[5,8,9,12,13,19,20]$. Any adverse events during the follow-up period were addressed.

\section{Data Analysis}

All statistical analyses were conducted in SPSS version 26.0 (IBM Corp., Armonk, NY, USA). The Student t test and Mann-Whitney U test were used to evaluate the differences between pure cysts and predominantly cystic nodules, except for the variables of viscosity, vascularity, transient burning sense (TBS), and therapeutic success rate (TSR), which were analyzed using the chi-square test. The Wilcoxon signed-rank test was used compare changes in nodule volume, symptom scores, and cosmetic scores from the initial status to the last follow-up after EA. Multiple linear regression analysis was performed to identify independent predictors of VRR, including initial volume, viscosity of the internal contents, color of the aspirate, vascularity, amount of ethanol, ethanol retention time, and presence of TBS during EA. All statistical tests were two-tailed, and P-values $<0.05$ were considered to indicate statistical significance.

\section{Results}

\section{Baseline Characteristics}

A summary of the baseline characteristics of the study population is shown in Table 1. The 61 nodules comprised 38 pure cysts and 23 predominantly cystic nodules in 60 patients. One female patient underwent EA for bilateral symptomatic cystic nodules on different

Table 1. Baseline characteristics and methods of ethanol ablation overall and in subgroups of cystic thyroid nodules

\begin{tabular}{|c|c|c|c|c|}
\hline Characteristic & Total $(n=61)$ & Pure cysts $(n=38)$ & Predominantly cystic nodules $(n=23)$ & P-value ${ }^{a)}$ \\
\hline Age (year) & $43.1 \pm 11.7$ & $45.3 \pm 11.9$ & $39.3 \pm 10.6$ & 0.051 \\
\hline $\operatorname{Sex}(M: F)$ & $18: 43$ & $12: 26$ & $6: 17$ & 0.649 \\
\hline Follow-up period (month) & $10.5 \pm 13.4$ & $11.0 \pm 14.7$ & $9.7 \pm 11.2$ & 0.687 \\
\hline Viscosity & & & & 0.356 \\
\hline Watery & $6(9.8)$ & $3(7.9)$ & $3(13.0)$ & \\
\hline Mucoserous & $41(67.2)$ & $24(63.2)$ & $17(73.9)$ & \\
\hline Sticky & $14(23.0)$ & $11(28.9)$ & $3(13.0)$ & \\
\hline Color & & & & 0.414 \\
\hline Pale yellowish & $3(4.9)$ & $3(7.9)$ & 0 & \\
\hline Brownish & $5(8.2)$ & $3(7.9)$ & $2(8.7)$ & \\
\hline Dark bloody & $32(52.5)$ & $21(55.3)$ & $11(47.8)$ & \\
\hline Red bloody & $21(34.4)$ & $11(28.9)$ & $10(43.5)$ & \\
\hline Vascularity ${ }^{\text {b) }}$ & & & & $<0.001$ \\
\hline 0 & $50(82.0)$ & $36(94.7)$ & $14(60.9)$ & \\
\hline 1 & $4(6.6)$ & $2(5.3)$ & $2(8.7)$ & \\
\hline 2 & $7(11.5)$ & 0 & $7(30.4)$ & \\
\hline 3 & 0 & 0 & 0 & \\
\hline Amount of ethanol (mL) & $3.5 \pm 1.2$ & $3.1 \pm 1.2$ & $4.3 \pm 1.0$ & $<0.001$ \\
\hline Retention time (min) & $6.8 \pm 2.3$ & $6.9 \pm 2.3$ & $6.8 \pm 2.3$ & 0.868 \\
\hline Transient burning sense (\%) & 70.5 & 79.0 & 56.5 & 0.085 \\
\hline
\end{tabular}

Values are presented as mean \pm standard deviation or number (\%).

${ }^{a}$ Compared between pure cysts and predominantly cystic nodules. ${ }^{b}$ Vascularity was graded using four categories: grade 0, no intranodular vascularity; grade 1, perinodular vascularity only; grade 2 , intranodular vascularity $<50 \%$; grade 3 , intranodular vascularity $>50 \%$. 


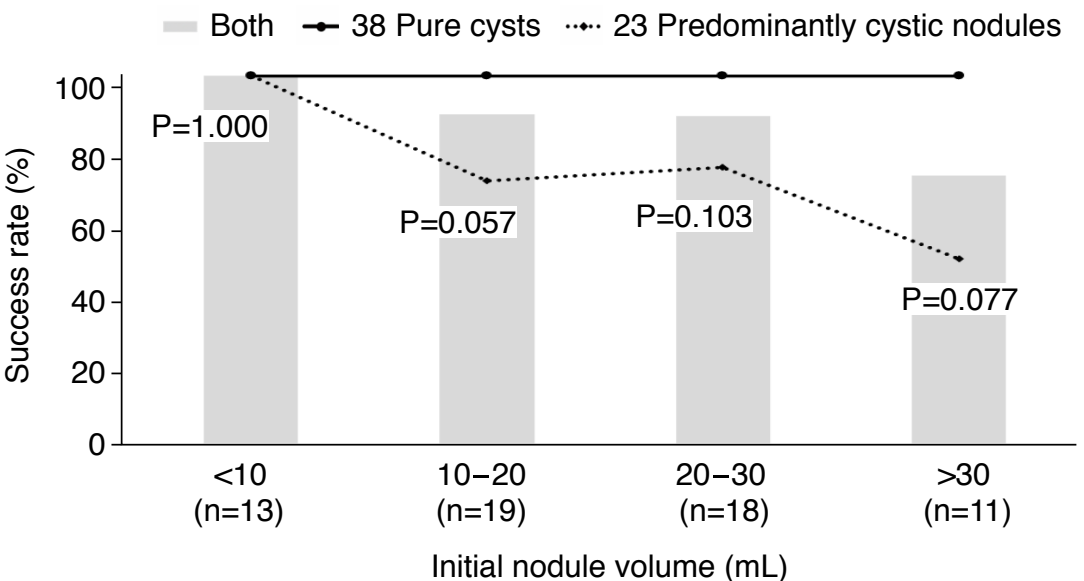

Fig. 3. Success rates of ethanol ablation by initial nodule volume (overall and subgroups). Success was defined as the disappearance of the cystic component, or a nodule volume reduction greater than $50 \%$ at the end of follow-up with improvement of nodule-related symptoms. Regardless of the target nodule volume, the success rate reached $100 \%$ in all pure cysts. In predominantly cystic nodules, the success rate showed a tendency to decrease as the target nodule volume increased. In each volume fraction, a comparison between subgroups showed no statistically significant differences ( $P$-values calculated by the Mann-Whitney $\mathrm{U}$ test).

Table 2. Outcomes of ethanol ablation overall and in subgroups of cystic thyroid nodules

\begin{tabular}{|c|c|c|c|c|c|c|}
\hline & \multicolumn{2}{|c|}{ Total $(n=61)$} & \multicolumn{2}{|c|}{ Pure cysts $(n=38)$} & \multicolumn{2}{|c|}{ Predominantly cystic nodules $(n=23)$} \\
\hline & Initial & Final & Initial & Final & Initial & Final \\
\hline Symptom score & $5.3 \pm 1.8$ & $1.1 \pm 1.8^{\mathrm{a})}$ & $5.0 \pm 1.9$ & $0.6 \pm 1.1^{\mathrm{a})}$ & $5.7 \pm 1.5$ & $1.8 \pm 2.4^{\mathrm{a})}$ \\
\hline Cosmetic score & $3.7 \pm 0.6$ & $1.5 \pm 0.9^{\mathrm{a})}$ & $3.6 \pm 0.6$ & $1.2 \pm 0.6^{\mathrm{a}}$ & $3.7 \pm 0.5$ & $1.9 \pm 1.2^{\mathrm{a})}$ \\
\hline Nodule volume (mL) & $21.9 \pm 15.2$ & $4.8 \pm 9.4^{\mathrm{a})}$ & $19.6 \pm 15.8$ & $1.6 \pm 2.2^{\mathrm{a})}$ & $25.7 \pm 13.6$ & $10.2 \pm 13.5^{\mathrm{a})}$ \\
\hline Therapeutic success (\%) & \multicolumn{2}{|c|}{88.5} & \multicolumn{2}{|c|}{100} & \multicolumn{2}{|c|}{$69.6^{\mathrm{b})}$} \\
\hline
\end{tabular}

Values are presented as mean \pm standard deviation.

${ }^{a)} \mathrm{P}<0.001$ for initial vs. final status. ${ }^{\text {b) }} \mathrm{P}<0.001$ for pure cysts vs. predominantly cystic nodules.

days. The mean initial volume was $21.9 \pm 15.2 \mathrm{~mL}$ (range, 4.4 to $77.2 \mathrm{~mL}$ ). The mean follow-up period was $10.5 \pm 13.4$ months (range, 1 to 66 months). In predominantly cystic nodules, the proportion of cystic composition was $80.0 \% \pm 13.8 \%$ (range, $40 \%$ to $90 \%$ ). The internal fluid contents were watery in six cysts, mucoserous in 41 cysts, and sticky (colloid) in 14 cysts. The color of the aspirate was pale yellowish in three cysts, brownish in five cysts, dark bloody in 32 cysts, and red bloody in 21 cysts. Most of the nodules ( $n=50$, $82.0 \%$ ) showed no vascularity. Predominantly cystic nodules had a significantly higher proportion of vascular lesions than pure cysts $(P<0.001)$. Viscosity $(P=0.356)$ and color $(P=0.414)$ showed no significant differences between the two subgroups.

\section{Usage of Ethanol during EA}

The mean amount of ethanol was $3.5 \pm 1.2 \mathrm{~mL}$ (range, 1 to $5 \mathrm{~mL}$ ) and the mean retention time was $6.8 \pm 2.3$ minutes (range, 0.9 to 13.0 minutes). The amount of ethanol according to the size of the cystic nodule was $2.5 \pm 0.9 \mathrm{~mL}$ (range, 2 to $5 \mathrm{~mL}$ ) in 13 nodules with a volume below $10 \mathrm{~mL}, 3.2 \pm 0.9 \mathrm{~mL}$ (range, 2 to $5 \mathrm{~mL}$ ) in 19 nodules with a volume of $10-20 \mathrm{~mL}, 3.8 \pm 1.3 \mathrm{~mL}$ (range, 1 to $5 \mathrm{~mL}$ ) in 18 nodules with a volume of $20-30 \mathrm{~mL}$, and $4.9 \pm 0.3 \mathrm{~mL}$ (range, 4 to 5 $\mathrm{mL}$ ) in 11 nodules with a volume over $30 \mathrm{~mL}$. The amount of ethanol used was greater in predominantly cystic nodules $(4.3 \pm 1.0 \mathrm{~mL})$ than in pure cysts $(3.1 \pm 1.2 \mathrm{~mL}, \mathrm{P}<0.001)$. In predominantly cystic nodules, the volume of ethanol used was $3 \pm 0 \mathrm{~mL}$ in two nodules with a volume below $10 \mathrm{~mL}, 3.9 \pm 1.1 \mathrm{~mL}$ (range, 3 to $5 \mathrm{~mL}$ ) in seven nodules with a volume of $10-20 \mathrm{~mL}, 4.5 \pm 0.9 \mathrm{~mL}$ (range, 3 to $5 \mathrm{~mL}$ ) in eight nodules with a volume of $20-30 \mathrm{~mL}$, and $4.8 \pm 0.4 \mathrm{~mL}$ (range, 4 to $5 \mathrm{~mL}$ ) in six nodules with a volume over $30 \mathrm{~mL}$. There was no significant difference in retention time between the two subgroups $(P=0.868)$.

\section{Treatment Outcomes}

The results of EA are summarized in Table 2. The overall TSR was $88.5 \%$. In pure cysts, a TSR of $100 \%$ was noted, which was significantly different from the TSR of $69.6 \%$ in predominantly cystic nodules $(P<0.001)$. The nodule volume decreased significantly from $21.9 \pm 15.2 \mathrm{~mL}$ (range, 4.4 to $77.2 \mathrm{~mL}$ ) to $4.8 \pm 9.4 \mathrm{~mL}$ (range, 0 to $44.6 \mathrm{~mL})$. The mean symptom score $(P<0.001)$ and cosmetic score $(\mathrm{P}<0.001)$ also showed significant improvements at the last followup.

The TSR was $100 \%$ in pure cysts regardless of the initial nodule volume, and tended to decrease in predominantly cystic nodules as the volume of the nodule increased (Fig. 3). The TSR of predominantly cystic nodules was $71.4 \%$ in seven nodules with a volume of $10-20 \mathrm{~mL}, 75.0 \%$ in eight nodules with a volume of 
$20-30 \mathrm{~mL}$, and $50.0 \%$ in six nodules with a volume over $30 \mathrm{~mL}$. In predominantly cystic nodules, successful treatment was achieved in 10 of 12 nodules (83.3\%) with a cystic portion of $80 \%-90 \%$, five of five nodules (100\%) with a cystic portion of $70 \%-80 \%$, zero of two nodules (0\%) with a cystic portion of $60 \%-70 \%$ and one of four nodules $(25.0 \%)$ with a cystic portion below $60 \%$.

The overall TSR was $100 \%$ in 13 nodules smaller than $10 \mathrm{~mL}$, and then tended to decrease as the initial nodule volume increased: $89.5 \%$ in 19 nodules with a volume of $10-20 \mathrm{~mL}, 88.9 \%$ in 18 nodules with a volume of $20-30 \mathrm{~mL}$, and $72.7 \%$ in 11 nodules with a volume of $30 \mathrm{~mL}$. However, within each volume group, there was no statistically significant difference between pure cysts and predominantly cystic nodules $(P>0.05)$.

\section{VRR and VRR-Related Factors}

The overall mean VRR was $80.7 \% \pm 26.1 \%$ (range, $4.1 \%$ to $100 \%$ ) at the last follow-up. The mean VRR was $90.1 \% \pm 12.3 \%$ (range, $53.8 \%$ to $100 \%$ ) in pure cysts and $65.1 \% \pm 34.5 \%$ (range, $4.1 \%$ to $99.0 \%$ in predominantly cystic nodules, which was a statistically significant difference $(P<0.001)$. Multiple linear regression analysis showed that vascularity $(P=0.010)$ was the only independent predictor of VRR in predominantly cystic nodules, whereas no factor was significantly associated with VRR in pure cysts (Table 3).

\section{Nodules Unresponsive to EA}

Seven predominantly cystic nodules (11.5\%) were classified as showing treatment failure because they did not meet the criterion for success due to a low VRR $(17.3 \% \pm 11.6 \%)$. The decision to perform an additional procedure was made at least 3 months after treatment. If a patient complained of nodule-related discomfort, the additional treatment was conducted as soon as possible after the decision was made. If not, in consideration of the fact that the treated cystic nodules were benign, whether to perform additional treatment and the timing of the treatment were decided in consultation with the patient.

For six of these seven nodules, additional ablative procedures were performed (additional EA in three nodules, RFA in two nodules, and combined additional EA and RFA in one nodule), while one patient refused further treatment. Five of the additional procedures were performed slightly more than 3 months after the initial treatment. One additional EA procedure was done at the point of 29 months of follow-up.

In principle, RFA was performed as an additional procedure in unresponsive nodules that contained a solid component of more than $20 \%$ [7]. However, one hemorrhagic nodule showing bloody aspirate had been treated with additional EA prior to RFA for the purpose of bleeding control inside the nodule [21]. All additional EA procedures were performed in the same manner using low-dose ethanol.

\section{Complications}

Complications and side effects were defined according to the quality improvement guidelines of the Society of Interventional Radiology [22]. In the current study, complications developed in five (8.2\%) patients, but none of the complications were permanent.

\section{Minor Complications}

Intra-cystic hemorrhage was observed in four cases (one pure cyst and three predominantly cystic nodules) during the procedure, but recovered within a week. During EA, 43 patients (70.5\%) experienced TBS within a few seconds after the injection of ethanol, which needs to be differentiated from acute severe pain that could be a sign of leakage. TBS mostly subsided within 10 minutes. A higher proportion of TBS was noted in the pure cystic group (79.0\%)

Table 3. Multivariate analysis of factors independently related to the volume reduction rate of ethanol ablation in subgroups of cystic thyroid nodules

\begin{tabular}{|c|c|c|c|c|}
\hline & \multicolumn{2}{|c|}{ Pure cysts $(n=38)$} & \multicolumn{2}{|c|}{ Predominantly cystic nodules $(n=23)$} \\
\hline & $\beta \pm S E$ & P-value & $\beta \pm S E$ & P-value \\
\hline Volume reduction rate (\%) & \multicolumn{2}{|c|}{$90.1 \pm 12.3^{\mathrm{a})}$} & \multicolumn{2}{|c|}{$65.1 \pm 34.5^{\mathrm{a})}$} \\
\hline Initial nodule volume & $0.171 \pm 0.181$ & 0.352 & $0.039 \pm 0.538$ & 0.943 \\
\hline Viscosity & $-3.676 \pm 3.839$ & 0.346 & $0.536 \pm 13.530$ & 0.969 \\
\hline Color & $1.900 \pm 2.105$ & 0.374 & $-3.732 \pm 10.408$ & 0.725 \\
\hline Vascularity & $2.441 \pm 9.508$ & 0.799 & $-23.215 \pm 7.866$ & 0.010 \\
\hline Amount of ethanol & $-1.335 \pm 2.364$ & 0.577 & $-5.271 \pm 8.114$ & 0.526 \\
\hline Retention time & $0.021 \pm 0.022$ & 0.342 & $0.089 \pm 0.058$ & 0.148 \\
\hline Transient burning sense & $6.635 \pm 7.280$ & 0.369 & $24.707 \pm 14.295$ & 0.104 \\
\hline
\end{tabular}

${ }^{2} \mathrm{P}<0.001$ for pure cystic vs. predominantly cystic nodules. 
Table 4. Judgments of success (ethanol ablation for cystic thyroid nodules) in the literature

\begin{tabular}{|c|c|c|c|c|c|c|}
\hline Method & Study & $\begin{array}{l}\text { No. of } \\
\text { cases }\end{array}$ & Sessions & VRR (\%) & $\begin{array}{l}\text { Success } \\
\text { rate (\%) }\end{array}$ & Definition of success or cure \\
\hline \multirow[t]{18}{*}{ Injection only } & Yasuda et al. (1992) [11] & 61 & 1.26 & - & 72 & Cystic lesion almost disappeared or decreased in size \\
\hline & Verde et al. (1994) [8] & 32 & 1 & 71 & 80 & Volume reduction $>50 \%$ \\
\hline & Antonelli et al. (1994) [12] & 26 & $1-5$ & - & 77 & Volume reduction $>50 \%$ or no residual fluid \\
\hline & Zingrillo et al. (1996) [15] & 20 & 1.7 & - & 95 & Volume reduction $>50 \%$ \\
\hline & Zingrillo et al. (1999) [16] & 43 & 1.5 & 91.9 & 93 & $\begin{array}{l}\text { Volume reduction with Improvement of compressive } \\
\text { symptoms }\end{array}$ \\
\hline & Cho et al. (2000) [23] & 22 & 1.2 & 64 & - & Not defined \\
\hline & Del Prete et al. (2002) [13] & 98 & 1.8 & - & 94 & Volume reduction $>50 \%$ \\
\hline & Chu et al. (2003) [24] & 10 & 2.4 & - & 90 & Not defined \\
\hline & Kim et al. (2003) [25] & 20 & 1.8 & 64 & - & Not defined \\
\hline & Guglielmi et al. (2004) [26] & 58 & 2.2 & 75 & 91.4 & $\begin{array}{l}\text { Volume reduction }>75 \% \text { and Improvement of pressure } \\
\text { symptoms }\end{array}$ \\
\hline & Valcavi and Frasoldati (2004) [18] & 266 & $1-3$ & 85.6 & $74.8 \mathrm{a} / 80 \mathrm{~b}$ & Improvement of cosmetic (a) and compressive (b) symptoms \\
\hline & Kim et al. (2005) [4] & 30 & 1 & - & 96.7 & Complete nodule disappearance \\
\hline & Jayesh et al. (2009) [19] & 15 & $1-2$ & - & 86.6 & Volume reduction $>50 \%$ \\
\hline & Basu et al. (2014) [27] & 60 & $1-2$ & $74.6 \mathrm{a} / 46.7 \mathrm{~b}$ & 78.3 & $\begin{array}{l}\text { Volume reduction }>50 \% \text { (a: pure cysts, b: predominantly } \\
\text { cystic nodules) }\end{array}$ \\
\hline & Perez et al. (2014) [28] & 120 & 2.8 & $66.7 a / 63 b$ & 70 & $\begin{array}{l}\text { Volume reduction }>70 \% \text { (a: pure cysts, b: predominantly } \\
\text { cystic nodules) }\end{array}$ \\
\hline & Halenka et al. (2015) [29] & 33 & 1.5 & 92.6 & 100 & No residual fluid \\
\hline & Felicio et al. (2016) [30] & 52 & 2.8 & 44.5 & 75 & $\begin{array}{l}\text { Volume reduction }>30 \% \text { with disappearance of clinical } \\
\text { symptoms }\end{array}$ \\
\hline & Park et al. (2019) [31] $]^{\text {a) }}$ & 108 & 1 & 83.2 & 88.9 & Volume reduction $>50 \%$ \\
\hline \multirow[t]{10}{*}{$\begin{array}{l}\text { Retention and } \\
\text { removal }\end{array}$} & Monzani et al. (1994) [2] & 20 & $1-2$ & - & 95 & Significant shrinkage \\
\hline & Bennedbaek and Hegedus (2003) [9] & 33 & $1-2$ & 100 & $64 a / 82 b$ & Cyst volume $<1 \mathrm{~mL}$ (a: single session, b: multiple sessions) \\
\hline & Lee and Ahn (2005) [14] & 432 & 2.3 & 73.2 & 88.9 & Volume reduction $>50 \%$ \\
\hline & Kim et al. (2005) [4] & 30 & 1 & - & 93.3 & Complete nodule disappearance \\
\hline & Kanotra et al. (2008) [32] & 40 & 1.5 & 70 & 89 & Improvement of cosmetic symptom \\
\hline & Sung et al. (2011) [20] & 36 & 1.19 & 93.1 & 94.4 & Volume reduction $>50 \%$ \\
\hline & Kim et al. (2012) [5] & 217 & $1-3$ & 85.2 & 90.3 & Volume reduction $>50 \%$ \\
\hline & Sung et al. (2013) [10] & 25 & 1 & 96.9 & 100 & Volume reduction and symptom improvement \\
\hline & Park et al. (2019) [31] & 113 & 1 & 86.1 & 77.9 & Volume reduction $>50 \%$ \\
\hline & Current study (2020) & 61 & 1 & 79.8 & 88.5 & $\begin{array}{l}\text { Volume reduction }>50 \% \text { or no residual fluid with } \\
\text { Improvement of symptoms }\end{array}$ \\
\hline
\end{tabular}

VRR, volume reduction rate.

${ }^{\text {a) }}$ Study comparing two modalities.

than in the predominantly cystic group (56.5\%), but there was no statistically significant difference $(P=0.085)$ (Table 1). Furthermore, TBS was not significantly related to VRR in either subgroup ( $P=0.335$ in the pure cystic group and $\mathrm{P}=0.075$ in the predominantly cystic group) (Table 3).

\section{Major Complications}

There were no serious complications such as voice change, skin burns, or subcutaneous abscess formation, except for one patient with cardiac arrhythmia. The patient started to complain of palpitation and dizziness about 30 seconds after the injection of 1 $\mathrm{mL}$ of ethanol. The heart rate increased to 150 beats/min without altered mental status. We discontinued the procedure by evacuating the ethanol immediately after recognizing the changes in the patient's status. The retention time was 55 seconds (the shortest among the study participants). The patient was transferred to the 
Table 5. Methods of ethanol ablation for cystic thyroid nodules in the literature

\begin{tabular}{|c|c|c|c|c|c|c|}
\hline Method & Study & $\begin{array}{c}\text { Ethanol } \\
(\%)\end{array}$ & $\begin{array}{c}\text { Initial volume } \\
(\mathrm{mL})\end{array}$ & $\begin{array}{c}\text { Ethanol } \\
\text { calculation }\end{array}$ & $\begin{array}{c}\text { Mean ethanol } \\
(\mathrm{mL})\end{array}$ & $\begin{array}{c}\text { Retention time } \\
\text { (min) }\end{array}$ \\
\hline \multirow[t]{18}{*}{ Injection only } & Yasuda et al. (1992) [11] & 99.9 & 13.2 & $10 \%$ & - & - \\
\hline & Verde et al. (1994) [8] & 95 & 16.6 & $1-10 \mathrm{~mL}$ & 3.5 & - \\
\hline & Antonelli et al. (1994) [12] & 99.9 & $16.8 \pm 9.9$ & $10 \%-33 \%$ & - & - \\
\hline & Zingrillo et al. (1996) [15] & 95 & $39 \pm 24$ & $2-4 \mathrm{~mL}$ & 5.2 & - \\
\hline & Zingrillo et al. (1999) [16] & 95 & $38.4 \pm 32.5$ & $2-4 \mathrm{~mL}$ & 7.4 & - \\
\hline & Cho et al. (2000) [23] & - & 13 & $40 \%-100 \%$ & $1-14$ & - \\
\hline & Del Prete et al. (2002) [13] & 95 & $35.2 \pm 20.1$ & $70 \%-150 \%$ & 14.9 & - \\
\hline & Chu et al. (2003) [24] & 95 & $17.3 \pm 11.4$ & $10 \%$ & - & - \\
\hline & Kim et al. (2003) [25] & 99.9 & 15.7 & $63.4 \%$ & - & - \\
\hline & Guglielmi et al. (2004) [26] & 95 & $13.7 \pm 14.0$ & $25 \%(<10 \mathrm{~mL})$ & 7.3 & - \\
\hline & Valcavi and Frasoldati (2004) [18] & 95 & $19.0 \pm 19.0$ & $50 \%-70 \%$ & - & - \\
\hline & Kim et al. (2005) [4] & 99.9 & 16.5 & $\leq 100 \%(\leq 20 \mathrm{~mL})$ & 8.3 & - \\
\hline & Jayesh et al. (2009) [19] & 95 & 10.4 & $50 \%$ & 4.8 & - \\
\hline & Basu et al. (2014) [27] & 100 & 8.04 & $50 \%-100 \%$ & 2.7 & - \\
\hline & Perez et al. (2014) [28] & 99.9 & $13.1 \pm 12.4$ & $33 \%$ & 6.2 & - \\
\hline & Halenka et al. (2015) [29] & 96 & $10.8 \pm 5.0$ & $20 \%-30 \%$ & 2.4 & - \\
\hline & Felicio et al. (2016) [30] & 99 & $13.2 \pm 12.5$ & $30 \%$ & 9.1 & - \\
\hline & Park et al. (2019) [31] ${ }^{b)}$ & 99 & $18.0 \pm 29.9$ & $50 \%$ & - & - \\
\hline \multirow[t]{10}{*}{ Retention and removal } & Monzani et al. (1994) [2] & 95 & $10-15$ & $33 \%$ & - & 5 \\
\hline & Bennedbaek and Hegedus (2003) [9] & 99 & 26 & - & - & 2 \\
\hline & Lee and Ahn (2005) [14] & 99.9 & $15.6 \pm 12.6$ & $40 \%-100 \%$ & 3.1 & 2 \\
\hline & Kim et al. (2005) [4] & 99.9 & 7.3 & $\leq 100 \%(\leq 20 \mathrm{~mL})$ & 5.4 & 10 \\
\hline & Kanotra et al. (2008) [32] & 95 & $12.3 \pm 3.6$ & $50 \%$ & - & - \\
\hline & Sung et al. (2011) [20] & $95-99$ & $13.8 \pm 12.0$ & $50 \%$ & - & 10 \\
\hline & Kim et al. (2012) [5] & 99.9 & $15.7 \pm 18.1$ & $50 \%$ & - & $2,5,10$ \\
\hline & Sung et al. (2013) [10] & $95-99$ & $12.1 \pm 11.0$ & $50 \%$ & - & 10 \\
\hline & Park et al. (2019) [31] ${ }^{b)}$ & 99 & $18.3 \pm 17.6$ & $50 \%$ & - & $2-5$ \\
\hline & Current study (2020) & 99.5 & $21.9 \pm 15.2$ & $1-5 \mathrm{~mL}$ & 3.5 & 6.8 \\
\hline
\end{tabular}

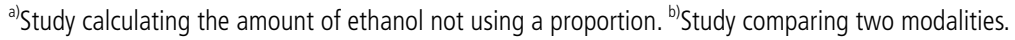

emergency department and hospitalized for 1 day of observation, and then completely recovered without sequelae.

\section{Discussion}

Many studies have reported that EA is effective and safe for treating symptomatic thyroid cystic nodules (Table 4). The reported TSR is $70 \%-100 \%$, the reported VRR is $44.5 \%-100 \%$, and the reported complication rate is $9 \%-34.6 \%[2,4,5,8-16,18-21,23-32]$. In the current study using low-dose ethanol in a single session, the TSR $(88.5 \%)$ was similar to the reported results and the complication rate $(8.2 \%)$ was lower. Regardless of the nodule volume and properties of the aspirate, low dose single-session EA showed high efficacy, especially for pure cysts, in which the TSR reached $100 \%$.

Many factors related to the standardization of the procedure remain unclear, with considerable variation in the literature (e.g., ethanol concentration, amount of ethanol injection, ethanol retention time, whether the injected ethanol is removed, and the definition of therapeutic success) (Table 5). The amount of ethanol instilled has been mostly chosen based on certain proportions to the amount of aspirate or nodule volume, with ranges of $10 \%-150 \%$ and 1-20 mL, respectively. Zingrillo et al. $[15,16]$ achieved a high TSR (95\%) using a small amount of ethanol. They determined the amount of ethanol to be injected according to the nodule volume: less than $2 \mathrm{~mL}$ of ethanol for cystic nodules with a volume less than $20 \mathrm{~mL} ; 3 \mathrm{~mL}$ for cystic nodules with a volume of $20-30 \mathrm{~mL}$; 
and $4 \mathrm{~mL}$ for cystic nodules with a volume over $30 \mathrm{~mL}$. The mean amount of ethanol used was 5.2-7.4 mL because their treatments were performed in multiple sessions $[15,16]$. Lee and Ahn [14] investigated 432 thyroid complex cysts, and found no relationship between the amount of injected ethanol and the reduction in nodule volume. In addition, many studies injecting ethanol at a small proportion $(10 \%-33 \%)$ of the aspirate volume showed good results for EA, even though they did not use a fixed amount of ethanol $[2,11,12,24,26,28-30]$. The present study also used a small amount of ethanol (mean, $3.5 \mathrm{~mL}$; range, 1 to $5 \mathrm{~mL}$ ) for cystic thyroid nodules and showed similar efficacy. Therefore, it may be suggested that a small amount of ethanol is enough to treat cystic thyroid nodules.

However, most existing studies using small amounts of ethanol reported outcomes including the effects of multiple treatment sessions. Therefore, it has been challenging to determine whether low-dose ethanol really works, especially in single-session EA. In the literature, the research that best matches the concept of lowdose single-session EA was performed by Verde et al. [8], who achieved a TSR of $80 \%$ by using less than $10 \mathrm{~mL}$ of ethanol once (mean, $3.5 \mathrm{~mL}$ ) for cystic thyroid nodules (mean volume, 16.6 $\mathrm{mL}$ ). That technique is most similar to the technique presented in the current study, in which less than $5 \mathrm{~mL}$ of ethanol was used once, and the main difference between the techniques is whether the instilled ethanol was removed. Previous studies revealed that efficacy was not affected by the choice of technique in this regard $[4,31]$. However, retained ethanol, especially when a double puncture is used, can cause extrathyroidal ethanol leakage, resulting in pain, voice change, a feeling of intoxication, and periglandular fibrosis $[2,4,18,31,33,34]$. Furthermore, a longer retention time may increase the risks of complications related to manipulating the inserted needle, such as leakage of injected ethanol $[5,20]$. Hence, the optimal ways to achieve the effect of treatment while minimizing complications are (1) using a small amount of ethanol; (2) making a single-puncture using a three-way connector; and (3) evacuating the instilled ethanol after retention (at least 2 minutes).

The diversity of the reported success rate for EA in the literature might be related not only to the heterogeneous nature of cystic thyroid nodules, but also to differences in evaluating the outcomes [30]. The major criteria for judging the success of treatment, or whether a cure has been achieved, have been a VRR greater than $50 \%$, the improvement of nodule-related pressure or cosmetic symptoms, and the absence of a residual cystic component (Table 4). On the one hand, some studies used relatively strict criteria to judge success (e.g., complete nodule disappearance or near total absence of a cystic component $[<1 \mathrm{~mL}]$ ), but on the other hand, some researchers have unclearly defined success using ambiguous terms (e.g., a "significant shrinkage" or a "decrease in size") $[2,4,9,11]$. Considering that the nodule-related symptoms of cystic thyroid nodules mainly stem from an increasing cystic component, it would be more reasonable to use both changes of nodule volume and disappearance of fluid content, along with improvements of clinical symptoms, when evaluating the outcomes of EA.

Previous studies have suggested that factors related to the success of EA include the proportion of the solid portion, the initial volume, vascularity, the retention time of ethanol and the sufficient evacuation of internal content before ethanol instillation [7]. In most existing studies (Table 5), the mean volumes of the nodules treated were under $20 \mathrm{~mL}$, except for a few studies by Zingrillo et al. [15,16] (38.4-39 mL), Del Prete et al. [13] (35.2 $\mathrm{mL})$, Bennedbaek and Hegedus [9] (26 mL), and Suh et al. [35] (20.1 $\mathrm{mL})$. The threshold at which volume starts to influence the effectiveness of EA has been considered to be $10 \mathrm{~mL}$ in all types of cystic nodules and $20 \mathrm{~mL}$ in predominantly cystic nodules $[5,35]$. In the current study, the mean volume was $21.9 \mathrm{~mL}$ and 11 nodules $(18.0 \%)$ were over $30 \mathrm{~mL}$. Similar to other studies, the efficacy of single-session low-dose EA was lower in the nodules containing a solid component (predominantly cystic nodules). The increased vascularity of solid components may cause ethanol drainage, thus limiting the success of EA $[7,21]$. We obtained an equivalent result, finding that vascularity was an independent predictor of VRR. The differences between the current study and others are as follows: (1) in pure cysts, the efficacy remained high regardless of the target lesion volume; (2) in predominantly cystic nodules, although the changes were not statistically significant, the effectiveness started to decrease from $10 \mathrm{~mL}$ and remained unchanged until 10-30 mL, but plummeted at an initial volume of over $30 \mathrm{~mL}$; and (3) initial volume, retention time, and amount of ethanol were not significantly related to efficacy. Of particular note, even though less than $5 \mathrm{~mL}$ of ethanol was used in each case, we used more ethanol in predominantly cystic nodules than in pure cysts. Nonetheless, the latter showed better outcomes.

Localized pain during EA is the most common complication and can be a sign of ethanol leakage into the subcutaneous tissue $[7,14]$. However, acute pain needs to be differentiated from tolerable TBS radiating to the ear or neck, which might be observed in up to $71 \%$ of patients $[9,13,16]$. In the current study, $70.5 \%$ of patients experienced TBS. If patients had TBS, we assumed that the time when they stopped complaining of it was the end point of retention. However, TBS per se was not correlated with VRR. TBS needs to be investigated more precisely in future research to determine how this finding can be understood and applied in clinical practice.

One of our patients experienced arrythmia immediately after the instillation of ethanol, a previously unreported complication 
of thyroid EA, although a similar situation (bradycardia and sinus arrest) has been observed in the ethanol treatment of hepatocellular carcinoma. Ethanol-induced arrythmia is presumed to be related to the direct entry of ethanol into the blood vessels inside the cystic nodule. However, the mechanisms leading to arrhythmia remain obscure [36]. In our experience, even though the treatment seemed to be insufficient due to discontinuation of the procedure $(1 \mathrm{~mL}$ of ethanol with 55 -second retention), the final volume at 46 months of follow-up was $0.52 \mathrm{~mL}$ (vs. $25.58 \mathrm{~mL}$ initially). Paradoxically, we were able to see the possible efficacy of low-dose single-session EA due to this case of a complication.

The current study has several limitations. First, the retrospective single-center study design might have led to selection bias. Although we have found evidence for the possibility of using a small amount of ethanol in a single session, to support this approach, prospective studies evaluating the efficacy of consistent low-dose usage compared to higher doses need to be performed in the future. In addition, the included population was relatively small and the follow-up duration was short, which might limit the generalizability of our study results.

In conclusion, single-session EA using low-dose ethanol ( $\leq 5 \mathrm{~mL})$, regardless of the volume of target nodule or aspirate, was effective in the treatment of symptomatic cystic thyroid nodules. The efficacy was superior for pure cysts. When the existence of a solid component is noted, nodules showing lower vascularity are better candidates. These results may be useful in the process of preprocedural selection and planning for patients complaining of discomfort related to cystic thyroid nodules.

ORCID: Woojin Cho: https://orcid.org/0000-0002-9059-648X; Jung Suk Sim: https:// orcid.org/0000-0001-6803-3544; So Lyung Jung: https://orcid.org/0000-0002-32678399

\section{Author Contributions}

Conceptualization: Cho W, Sim JS, Jung SL. Data acquisition: Cho W. Data analysis or interpretation: Cho W, Jung SL. Drafting of the manuscript: Cho W, Jung SL. Critical revision of the manuscript: Cho W, Sim JS, Jung SL. Approval of the final version of the manuscript: all authors.

\section{Conflict of Interest}

No potential conflict of interest relevant to this article was reported.

\section{Acknowledgments}

We would like to acknowledge Dr. Yangsean Choi for assistance.

\section{References}

1. Kotewall N, Lang BH. High-intensity focused ultrasound ablation as a treatment for benign thyroid diseases: the present and future. Ultrasonography 2019;38:135-142.

2. Monzani F, Lippi F, Goletti O, Del Guerra P, Caraccio N, Lippolis PV, et al. Percutaneous aspiration and ethanol sclerotherapy for thyroid cysts. J Clin Endocrinol Metab 1994;78:800-802.

3. Rozman B, Bence-Zigman Z, Tomic-Brzac H, Skreb F, Pavlinovic Z, Simonovic I. Sclerosation of thyroid cysts by ethanol. Period Biol 1989;91:1116-1118.

4. Kim DW, Rho MH, Kim HJ, Kwon JS, Sung YS, Lee SW. Percutaneous ethanol injection for benign cystic thyroid nodules: is aspiration of ethanol-mixed fluid advantageous? AJNR Am J Neuroradiol 2005;26:2122-2127.

5. Kim YJ, Baek JH, Ha EJ, Lim HK, Lee JH, Sung JY, et al. Cystic versus predominantly cystic thyroid nodules: efficacy of ethanol ablation and analysis of related factors. Eur Radiol 2012;22:1573-1578.

6. In HS, Kim DW, Choo HJ, Jung SJ, Kang T, Ryu JH. Ethanol ablation of benign thyroid cysts and predominantly cystic thyroid nodules: factors that predict outcome. Endocrine 2014;46:107-113.

7. Hahn SY, Shin JH, Na DG, Ha EJ, Ahn HS, Lim HK, et al. Ethanol Ablation of the Thyroid Nodules: 2018 Consensus Statement by the Korean Society of Thyroid Radiology. Korean J Radiol 2019;20:609620.

8. Verde G, Papini E, Pacella CM, Gallotti C, Delpiano S, Strada S, et al. Ultrasound guided percutaneous ethanol injection in the treatment of cystic thyroid nodules. Clin Endocrinol (Oxf) 1994;41:719-724.

9. Bennedbaek FN, Hegedus L. Treatment of recurrent thyroid cysts with ethanol: a randomized double-blind controlled trial. J Clin Endocrinol Metab 2003;88:5773-5777.

10. Sung JY, Baek JH, Kim KS, Lee D, Yoo H, Kim JK, et al. Single-session treatment of benign cystic thyroid nodules with ethanol versus radiofrequency ablation: a prospective randomized study. Radiology 2013;269:293-300.

11. Yasuda K, Ozaki O, Sugino K, Yamashita T, Toshima K, Ito K, et al. Treatment of cystic lesions of the thyroid by ethanol instillation. World I Surg 1992;16:958-961.

12. Antonelli A, Campatelli A, Di Vito A, Alberti B, Baldi V, Salvioni G, et al. Comparison between ethanol sclerotherapy and emptying with injection of saline in treatment of thyroid cysts. Clin Investig 1994;72:971-974.

13. Del Prete S, Caraglia M, Russo D, Vitale G, Giuberti G, Marra M, et al. Percutaneous ethanol injection efficacy in the treatment of large symptomatic thyroid cystic nodules: ten-year follow-up of a large series. Thyroid 2002;12:815-821.

14. Lee SJ, Ahn IM. Effectiveness of percutaneous ethanol injection therapy in benign nodular and cystic thyroid diseases: long-term follow-up experience. Endocr J 2005;52:455-462. 
15. Zingrillo M, Torlontano M, Ghiggi MR, D'Aloiso L, Nirchio V, Bisceglia $M$, et al. Percutaneous ethanol injection of large thyroid cystic nodules. Thyroid 1996;6:403-408.

16. Zingrillo $M$, Torlontano $M$, Chiarella R, Ghiggi MR, Nirchio V, Bisceglia $M$, et al. Percutaneous ethanol injection may be a definitive treatment for symptomatic thyroid cystic nodules not treatable by surgery: five-year follow-up study. Thyroid 1999;9:763767.

17. Chung J, Lee YJ, Choi YJ, Ha EJ, Suh CH, Choi M, et al. Clinical applications of Doppler ultrasonography for thyroid disease: consensus statement by the Korean Society of Thyroid Radiology. Ultrasonography 2020;39:315-330.

18. Valcavi R, Frasoldati A. Ultrasound-guided percutaneous ethanol injection therapy in thyroid cystic nodules. Endocr Pract 2004; 10:269-275.

19. Jayesh SR, Mehta P, Cherian MP, Ilayaraja V, Gupta P, Venkatesh K. Efficacy and safety of USG-guided ethanol sclerotherapy in cystic thyroid nodules. Indian J Radiol Imaging 2009;19:199-202.

20. Sung JY, Kim YS, Choi H, Lee JH, Baek JH. Optimum first-line treatment technique for benign cystic thyroid nodules: ethanol ablation or radiofrequency ablation? AJR Am J Roentgenol 2011;196:W210-W214.

21. Park HS, Baek JH, Choi YJ, Lee JH. Innovative techniques for imageguided ablation of benign thyroid nodules: combined ethanol and radiofrequency ablation. Korean J Radiol 2017;18:461-469.

22. Saad WE, Wallace MJ, Wojak JC, Kundu S, Cardella JF. Quality improvement guidelines for percutaneous transhepatic cholangiography, biliary drainage, and percutaneous cholecystostomy. J Vasc Interv Radiol 2010;21:789-795.

23. Cho YS, Lee HK, Ahn IM, Lim SM, Kim DH, Choi CG, et al. Sonographically guided ethanol sclerotherapy for benign thyroid cysts: results in 22 patients. AJR Am J Roentgenol 2000;174:213216.

24. Chu CH, Chuang MJ, Wang MC, Lam HC, Lu CC, Lee JK. Sclerotherapy of thyroid cystic nodules. J Formos Med Assoc 2003; 102:625-630.

25. Kim JH, Lee HK, Lee JH, Ahn IM, Choi CG. Efficacy of sonographically guided percutaneous ethanol injection for treatment of thyroid cysts versus solid thyroid nodules. AJR Am J Roentgenol 2003;180:1723-1726.
26. Guglielmi R, Pacella CM, Bianchini A, Bizzarri G, Rinaldi R, Graziano $F M$, et al. Percutaneous ethanol injection treatment in benign thyroid lesions: role and efficacy. Thyroid 2004;14:125-131.

27. Basu N, Dutta D, Maisnam I, Basu S, Ghosh S, Chowdhury S, et al. Percutaneous ethanol ablation in managing predominantly cystic thyroid nodules: an eastern India perspective. Indian J Endocrinol Metab 2014;18:662-668.

28. Perez $\mathrm{CL}$, Fighera TM, Miasaki F, Mesa Junior CO, Paz Filho GJ, Graf $\mathrm{H}$, et al. Evaluation of percutaneous ethanol injections in benign thyroid nodules. Arq Bras Endocrinol Metabol 2014;58:912-917.

29. Halenka M, Karasek D, Frysak Z. Ultrasound-guided percutaneous ethanol injection of small and medium-sized thyroid cysts with relatively small amounts of ethanol. Biomed Pap Med Fac Univ Palacky Olomouc Czech Repub 2015;159:417-421.

30. Felicio JS, Conceicao AM, Santos FM, Sato MM, Bastos Fde A, Braga de Souza AC, et al. Ultrasound-guided percutaneous ethanol injection protocol to treat solid and mixed thyroid nodules. Front Endocrinol (Lausanne) 2016;7:52.

31. Park HS, Yim Y, Baek JH, Choi YJ, Shong YK, Lee JH. Ethanol ablation as a treatment strategy for benign cystic thyroid nodules: a comparison of the ethanol retention and aspiration techniques. Ultrasonography 2019;38:166-171.

32. Kanotra SP, Lateef M, Kirmani O. Non-surgical management of benign thyroid cysts: use of ultrasound-guided ethanol ablation. Postgrad Med J 2008;84:639-643.

33. Bennedbaek FN, Hegedus L. Percutaneous ethanol injection therapy in benign solitary solid cold thyroid nodules: a randomized trial comparing one injection with three injections. Thyroid 1999;9:225233.

34. Mauz PS, Stiegler M, Holderried M, Brosch S. Complications of ultrasound guided percutaneous ethanol injection therapy of the thyroid and parathyroid glands. Ultraschall Med 2005;26:142-145.

35. Suh CH, Baek JH, Ha EJ, Choi YJ, Lee JH, Kim JK, et al. Ethanol ablation of predominantly cystic thyroid nodules: evaluation of recurrence rate and factors related to recurrence. Clin Radiol 2015;70:42-47.

36. Ferlitsch A, Kreil A, Bauer $E$, Schmidinger $H$, Schillinger $M$, Gangl $A$, et al. Bradycardia and sinus arrest during percutaneous ethanol injection therapy for hepatocellular carcinoma. Eur J Clin Invest 2004;34:218-223. 